\title{
REQUEST FOR NOMINATIONS
}

Members are invited to send to the MESA Secretariat nominations for the Board of Directors and for the President-Elect. These will be submitted to the 1978 Nominating Committee, when elected. The deadline for receiving nominations is April 1.

\section{PROGRAM COMMITTEE 1978}

\section{INSTRUCTIONS FOR SUBMISSION OF PROPOSALS FOR PAPERS}

The Program Committee for the 1978 MESA Annual Meeting will maintain the procedures introduced last year for the submission and evaluation of papers.

1. All Abstracts (including the short Abstract) submitted for consideration must be received by the Program Committee no later than May 15, 1978, and must be accompanied by the preregistration fee of $\$ 14.00$ ( $\$ 6.00$ for students) in U.S. funds, check or money order.

2. All checks or money orders should be made payable to the "University of Michigan."

3. The Short Abstract must be submitted on the form provided* and must be reproduceable for publication, that is, typed in clean, black type, single-spaced within the specified margins.

4. Long Abstracts must be submitted with seven (7) copies for evaluation by the Program Committee.

All submissions and inquiries regarding the 1978 program should be addressed to:

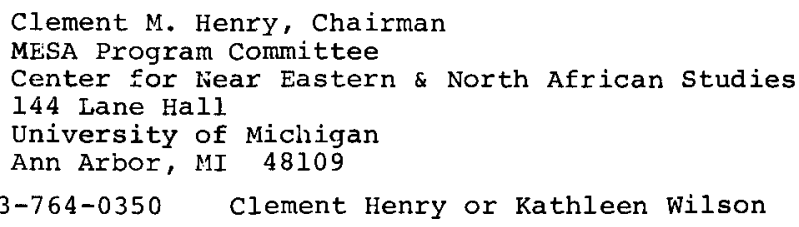

DEFINITIONS AND PROCEDURES

Part I. CATEGORIES OF PAPERS

The conference will be organized into three categories of presentation:

A. Panels: groups of papers on a common theme or problem. Each panelist will present a summary only of his paper of not more than 15 minutes. Papers will not be read. The remainder of the time will be devoted to discussion among the panelists, discussants and audience. Chairpersons will be responsible for the advance distribution of all panel papers among the participants. Panelists are to make extra copies of their papers available for sale to the general membership in accordance with the instructions in Part VI.

* Forms for typing abstracts were sent to the membership in a separate January mailing. Additional forms are available from the MESA Secretariat. 
B. Workshops: groups of presentations concerned with methodology and/or demonstrations of new approaches, techniques, technology, models, etc. Each participant will give a summary presentation only of not more than 15 minutes. The remainder of the time will be devoted to discussion among the participants, discussants, and audience. Panelists who have papers they wish to make avai1able for general distribution to the membership will follow the instructions in Part VI. Chairpersons will be responsible for advance distribution of available papers among the workshop participants.

C. Papers for Distribution and Discussion: individual papers submitted by their authors or as parts of panels or workshops which in the opinion of the Program committee do not fall into categories "A" or "B". These papers will be available for sale or distribution by the author at the conference. The authors will be given an opportunity to discuss their papers with any interested persons on Thursday afternoon, November 9, 1978 in rooms reserved for the purpose.

It should be emphasized that contributions submitted in any of the three categories will be considered "accepted" papers, and the authors will receive letters of acceptance from the Program Committee suitable to enable them to apply for conference funds from their institutions.

The Program Committee will determine which submissions are acceptable under all three categories. Only papers accepted under categories "A" and "B" above will be presented orally in organized sessions. Where feasible and desirable, the Program committee will attempt to organize miscellaneous papers into appropriate panels or workshops.

Part II. ABSTRACTS

All papers (in all three categories) require two abstracts.

A. Long Abstract for Evaluation: An abstract of 250-500 words with seven (7) copies is due by May 15, 1978, to the Chairperson of the Program Committee. This abstract will be evaluated "blind" by the Program Committee. Put name and address at top of page away from main body of type.

B. Short Abstract for Publication: An abstract of 75-100 words is to be typed on the accompanying "Short Abstract" form, for publication in the MESA Bulletin supplement, October 1978. One (1) copy of the Short Abstract should be included with the packet of Long Abstracts.

Part III. ORGANIZED SESSIONS

Panels and workshops must be submitted as a package to the Program Comnittee by the organizer by May 15, 1978. The package should include:

1. I copy of the Proposal for Organized Session form (both sides completed).

2. 7 copies of each Long Abstract

3. 1 copy of each Short Abstract

4. Individual pre-registration fees of panelists (check or money order) stapled to the short Abstract forms 
Part IV. PRE-PAID REGISTRATION FEE

All participants (in all three categories) must accompany their submitted abstracts with their registration fee for the conference. Members who intend to participate in any of the three categories may withdraw from participation without forfeiture of the pre-paid registration fee provided the Program Committee is informed in writing prior to September 1, 1978. All participants who withdraw after that date will forfeit their registration fee. This is intended to reduce the increasing number of "no-shows" at MESA Conferences.

Part $V$. INSTRUCTIONS FOR SLIDES

For those desiring to use slides, both single and double projection of $2 \times 2$ inch slides will be available. Due to time constraints, speakers are asked to use no more than 24 slides. Detailed instructions on slide presentations will be sent to those whose abstracts are accepted.

\section{Part VI. SALE AND DISTRIBUTION OF PAPERS}

Participants in categories " $\mathrm{C}$ " above must bring at least 25 copies of their papers to the conference for sale and/or distribution. Papers to be sold must be delivered to the sales table at the Michigan League by Thursday morning, November 9, 1978. Papers in categories "A" and "B" should also be made available for sale. Proceeds from the sale of the papers will be divided equally between MESA and the authors.

\section{Part VII, ASSOCIATED ORGANIZATIONS}

Associated organizations will be block scheduled for sessions and business meetings on Wednesday, November 8,1978 . They may request blocks of time ranging from one hour to all day. The requirements, procedures and schedules for any activities falling within an associated organization's assigned time block on Wednesday will be determined entirely by the associated organization and communicated to its membership.

Any proposals for panels, workshops, or other activities that associated organizations would like to initiate and sponsor jointly with MESA to meet during the MESA Conference itself (Thursday, November 9 through Saturday, November 11, 1978) must be submitted to the MESA Program Committee in accordance with the procedures described above (Parts II through VI) for approval and scheduling.

\section{Part VIII. PLENARY SESSION}

The Program Committee welcomes and solicits suggestions from the membership as to programs and speakers for the plenary session. Suggestions for a breakfast session will also be entertained. 